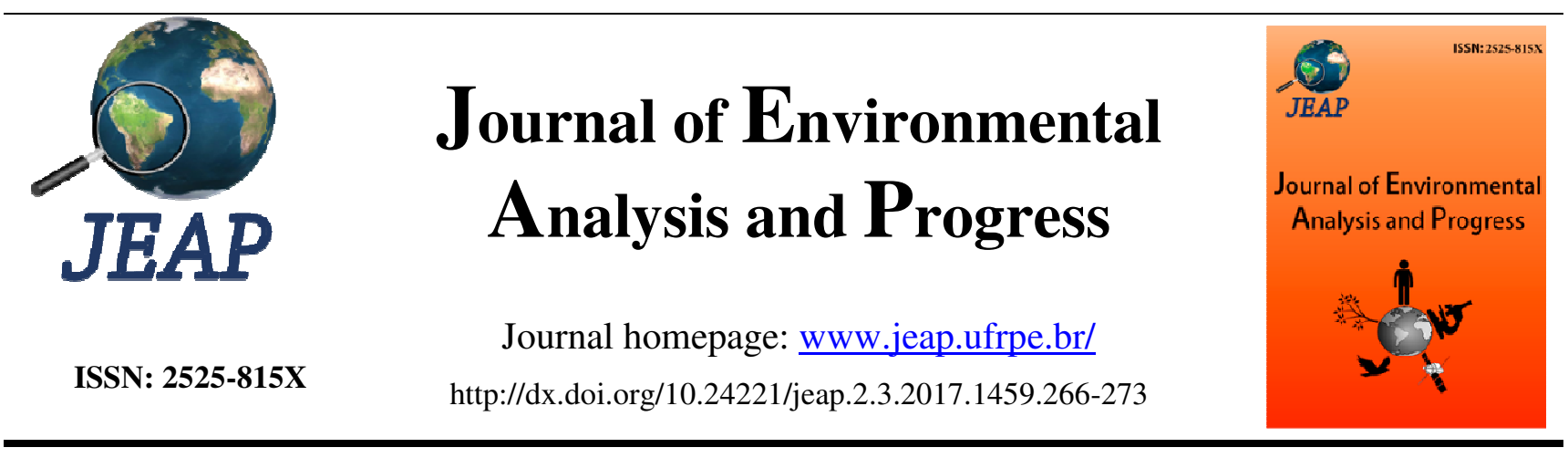

\title{
Simulação do efeito da variação da temperatura ambiente na germinação de variedades de milho
}

\section{Simulation of the effect of environmental temperature variation in the germination of corn varieties}

Junia Naara da Silva Carvalho ${ }^{a}$, José Aliçandro Bezerra da Silva ${ }^{a}$, Daíse Souza Reis ${ }^{\text {a }}$, Camila Coelho Guimarães ${ }^{\mathrm{b}}$, Ítalo Emannuel dos Anjos Santos ${ }^{\mathrm{a}}$

a Universidade Federal do Vale do São Francisco-UNIVASF, Colegiado de Engenharia Agrícola, Av. Antônio Carlos Magalhães, n. 510, Country Club, Juazeiro, Bahia, Brasil. CEP: 48902-300. E-mail: junianaara@ yahoo.com.br; dayse29@ hotmail.com; alissandrojbs@g-mail.com.

b Serviço Nacional de Aprendizagem Industrial-SENAI, Departamento de Cursos Técnicos em Manutenção Mecânica e Eletromecânica. Rua das Turbinas, n. 940, Bela Vista, Barreias-BA. CEP: 47811-003. E-mail: camilacguimaraes@hotmail.com.

A R T I C L E I N F O

Recebido 30 Jun 2017

Aceito 11 Jul 2017

Publicado 31 Jul 2017

\begin{abstract}
A B S T R A C T
Increases in room temperature may significantly influence the germination process of several plant species. It can directly interfere directly with physiological, biochemical and other activities, thus altering the maximum seed capacity to activate seedling emergence, as well as the morphological Plants. The objective of this study was to evaluate the effect of temperature on germination of three varieties of corn. It was used three different maize varieties: BRS Assum black, BRS011, and BRS033 Asa Branca. The treatments consisted of three controlled temperature: $20^{\circ} \mathrm{C}$ and $40^{\circ} \mathrm{C}$ and $30^{\circ} \mathrm{C}$. The variables analyzed were percentage of germination; germination speed index; mean germination time; germination frequency; height change and stem; stem diameter; number of leaves; chlorophyll $a, b$, overall; fresh and dry stem, leaf and root. The Tukey test was applied at $5 \%$, in the variables when significant. The $30^{\circ} \mathrm{C}$ temperature range is ideal for germination and early development of corn seedlings. The varieties studied do not differ significantly for dry mass production, except the roots, as well as the biometric variables. There are no differences between varieties in the production of chlorophyll. The temperature of 30 proved that influences the increased production of chlorophyll A and total; stem and leaves dry weight as well as the biometric variables.
\end{abstract}

Keywords: Emergence, seedling, variables, production.

\begin{abstract}
R E S U M O
Aumentos na temperatura ambiente podem influenciar de forma significativa o processo de germinação de diversas espécies vegetais. Podem interferir diretamente em atividades fisiológicas, bioquímicas entre outras, alterando desta forma a máxima capacidade das sementes em ativar a emergência das plântulas, bem como a formação morfológica das plantas. $\mathrm{O}$ objetivo desse estudo foi simular em câmaras de crescimento o efeito de diferentes temperaturas na germinação de três cultivares de milho: BRS Assum preto, BRS011 e BRS033 Asa Branca. O experimento foi implantado a partir da utilização dos tratamentos formados por três temperaturas controladas: $20^{\circ}, 30^{\circ}$ e $40^{\circ} \mathrm{C}$. As variáveis analisadas foram percentuais de germinação; índice de velocidade de germinação; tempo médio de
\end{abstract}


germinação; frequência de germinação; altura das plântulas; diâmetro do caule; número de folhas; clorofila $a, b$ e total; massa fresca e seca do caule, folha e raiz. O teste de Tukey a 5\% foi aplicado nas variáveis, quando significativas. A faixa de temperatura de $30^{\circ} \mathrm{C}$ é a ideal para a germinação e desenvolvimento inicial de mudas de milho. As variedades estudadas não apresentam diferenças significativas para a produção de massa seca, exceto a das raízes, bem como para as variáveis biométricas estudadas. Não há diferenças entre as variedades na produção de clorofilas. A temperatura de $30^{\circ} \mathrm{C}$ foi a que apresentou o maior índice de clorofila $\mathrm{A}$ e total; massa seca do caule e das folhas, assim como das variáveis biométricas.

Palavras-Chave: Emergência, plântula, variável, produção.

\section{Introdução}

Diversos estudos têm demonstrado que a variação da temperatura ambiente e da radiação pode influenciar de forma significativa a germinação de grande parte das espécies vegetais. As oscilações destes dois fatores podem inibir o crescimento das plântulas afetado todas as fases fenológicas que abrange o crescimento $\mathrm{e}$ desenvolvimentos das plantas. A temperatura pode ser considerada como um dos principais fatores determinantes da emergência das plântulas e da taxa de aparecimento de novas folhas. O milho (Zea mays), apesar de ser uma planta $\mathrm{C} 4$, também se enquadra entre as espécies com sementes que têm seu processo de germinação influenciado pela temperatura e radiação luminosa (Bergamaschi \& Matzenauer, 2014).

A determinação ecofisiológica das temperaturas mínimas, ótima e máxima para a germinação de sementes é fundamental para obter a capacidade máxima produtiva das plantas (Vazde-Mello, 2012). Guan et al. (2009) relatam que as baixas temperaturas induzem danos na membrana celular e afetam as funções fisiológicas das plantas, além de impedir o processo de germinação.

As sementes de milho geralmente morrem em poucos dias acima da temperatura máxima, e abaixo da temperatura mínima, as sementes não germinam em período razoável de tempo. A temperatura ótima recomendada no teste de germinação de sementes de milho é $25^{\circ} \mathrm{C}$ (Brasil, 2009).

Sbrussi \& Zucareli (2014), avaliando o efeito de diferentes temperaturas na germinação de sementes de milho, com níveis de vigor diferenciados, demonstram que as temperaturas baixas retardam a germinação das sementes do milho, não sendo observada germinação a $16{ }^{\circ} \mathrm{C}$. Todavia, Vaz-de-Mello et al. (2012), avaliando a germinação e vigor de sementes de milho-pipoca submetidas ao estresse térmico e hídrico, observaram que temperaturas de 20 e $35^{\circ} \mathrm{C}$ acarretam efeito negativo sobre o \% e velocidade de germinação e no crescimento das plântulas de milho pipoca. Nesse sentido, o objetivo desse estudo foi a partir da simulação de uma variação da temperatura e radiação ambiente, avaliar seus efeitos na germinação de três cultivares de milho.

\section{Material e Métodos}

$\mathrm{O}$ experimento foi conduzido na Universidade Federal do Vale do São Francisco, campus Juazeiro, Estado da Bahia. Os testes foram realizados no Laboratório de Citologia e Fisiologia Vegetal e em viveiro. No Laboratório, as sementes foram postas para germinar em câmara Incubadora para BOD (Demanda Bioquímica do Oxigênio), com temperatura controlada para $30^{\circ}$ e $40^{\circ} \mathrm{C}$ e em sala de crescimento para $20^{\circ} \mathrm{C}$.

As variedades de milho utilizadas foram: BRS Assum preto, BRS011 e BRS033 Asa Branca, todas provenientes do banco de germoplasma da Embrapa Semiárido. As sementes foram semeadas em copos plásticos descartáveis com capacidade para $50 \mathrm{~mL}$ e dispostas em bandejas identificadas para cada repetição em delineamento inteiramente casualizado com três repetições.

Os tratamentos consistiram em três variedades distintas e cinco ambientes para germinação e desenvolvimento inicial, com dez plantas por repetição, totalizando 450 plantas, dentre as quais, para as análises biométricas e as destrutivas foram utilizadas cinco referentes a cada repetição.

As variáveis analisadas foram percentuais de germinação; índice de velocidade de germinação; tempo médio de germinação e frequência de germinação. Estas foram realizadas diariamente desde o plantio até os 20 dias após a semeadura.

Após a finalização do período de germinação foram avaliadas as variáveis morfológicas: altura das plântulas, utilizando régua comum, diâmetro do caule por meio de um paquímetro digital e número de folhas determinado através de contagem manual.

A quantificação do Índice de clorofilas $a$, $b$ e total foi estimado através de equipamento digital clorofilômetro (Marca: Falker, Modelo: ClorofiLog), expressos pelo índice de clorofila Falker (ICF).

Para a determinação da massa fresca e seca do caule, folha e raiz, foram realizadas as 
pesagens do material fresco em balança de precisão digital, e posteriormente estes foram colocados em estufa à temperatura de $50^{\circ} \mathrm{C}$ para determinação da matéria seca.

Para as análises estatísticas o experimento foi dividido em duas etapas. Inicialmente, foi analisado em esquema fatorial $3 \times 3$ as variedades em interação com as temperaturas controladas, e, quando significativas às diferenças entre as interações, foi realizado o teste de Tukey a 5\% de probabilidade.

Os dados obtidos das plântulas conduzidas em viveiro, sombreado e não sombreado foram analisados separadamente apenas como comparativo com as demais, tendo em vista a variação na temperatura ao longo dos 20 dias de condução. Sendo utilizadas as médias como comparação com os demais tratamentos.

\section{Resultados}

Quanto aos dados de germinação conforme a Tabela 1, para as variáveis: Índice de Velocidade de Germinação (IVG) e Frequência Relativa de Germinação (FRG) não houve diferenças significativas na interação entre Variedade e Temperatura. No entanto, para as diferentes faixas de temperatura o melhor índice de velocidade de germinação se apresentou na faixa de $30^{\circ} \mathrm{C}$.

Tabela 1. Índice de Velocidade de Germinação e Frequência Relativa de Germinação em função em função das variedades de milho BRS Assum preto, BRS011 e BRS033 Asa Branca, e temperaturas de germinação. Petrolina-PE, em 2015.

\begin{tabular}{lcc}
\hline Variedades & $\begin{array}{c}\text { Índice de Velocidade de } \\
\text { Germinação }\end{array}$ & $\begin{array}{c}\text { Frequência Relativa de } \\
\text { Germinação }\end{array}$ \\
\hline BRS Assum preto & $2,3037^{\mathrm{a}}$ & $15,2076^{\mathrm{a}}$ \\
BRS011 & $2,4278^{\mathrm{a}}$ & $15,8991^{\mathrm{a}}$ \\
BRS033 Asa Branca & $3,2481^{\mathrm{a}}$ & $13,8830^{\mathrm{a}}$ \\
Temperatura & $1,7481^{\mathrm{b}}$ & $12,6645^{\mathrm{a}}$ \\
\hline $20^{\circ} \mathrm{C}$ & $3,5018^{\mathrm{a}}$ & $14,1762^{\mathrm{a}}$ \\
$30^{\circ} \mathrm{C}$ & $2,7296^{\mathrm{ab}}$ & $18,1490^{\mathrm{a}}$ \\
$40^{\circ} \mathrm{C}$ & 42,96 & 39,40 \\
\hline C.V.(\%) & $4 \%$ & $\mathrm{n}$ \\
\hline
\end{tabular}

*Médias seguidas de mesma letra não coluna não diferem entre si, pelo Teste de Tukey em nível de 5\% de probabilidade.

Entre as temperaturas avaliadas verificouse que as de $30^{\circ} \mathrm{C}$ e $40^{\circ} \mathrm{C}$ foram as que proporcionaram melhor velocidade de geminação para as sementes de milho das variedades BRS Assum preto, BRS011 e BRS033 Asa Branca. Podendo afirmar desta forma que estes níveis de temperatura apresentaram resposta positiva na ativação das etapas do processo de germinação das sementes de milho com consequente início de formação das plântulas.

$\mathrm{Na}$ Tabela 2, estão dispostos os dados da avaliação estatística do Tempo Médio de Germinação (TMG). Observa-se que o maior tempo de germinação foi obtido pela temperatura de $20^{\circ} \mathrm{C}$ para ambas as variedades e o menor tempo na temperatura de $40^{\circ} \mathrm{C}$ para as variedades BRS Assum preto e BRS011.

Tabela 2. Tempo Médio de Germinação (dias), em função das variedades de milho BRS Assum preto, BRS011 e BRS033 Asa Branca, e temperaturas de germinação. Petrolina-PE, em 2015.

\begin{tabular}{lccc}
\hline & \multicolumn{3}{c}{ Temperatura } \\
Variedades & $\mathbf{2 0}^{\circ} \mathbf{C}$ & $\mathbf{3 0}^{\circ} \mathbf{C}$ & $\mathbf{4 0}^{\mathbf{0}} \mathbf{C}$ \\
\hline BRS Assum preto & $6,0000^{\mathrm{aA}}$ & $4,6667^{\mathrm{aB}}$ & $3,3333^{\mathrm{bC}}$ \\
BRS011 & $6,0000^{\mathrm{aA}}$ & $4,6667^{\mathrm{aB}}$ & $3,0000^{\mathrm{bC}}$ \\
BRS033 Asa Branca & $6,0000^{\mathrm{aA}}$ & $4,6667^{\mathrm{aB}}$ & $5,0000^{\mathrm{aB}}$ \\
\hline C.V.(\%) & 7,99 & & \\
\hline
\end{tabular}

*Médias seguidas de mesma letra minúscula na coluna e maiúscula na linha não diferem entre si, pelo Teste de Tukey em nível de 5\% de probabilidade.

A variedade BRS Assum preto não apresentou diferença significativa na produção de Massa Fresca do Caule, da Folha, da Raiz e nem na Massa Seca da raiz nas temperaturas de $20^{\circ} \mathrm{C}$ e $30^{\circ} \mathrm{C}$, demonstrando decréscimo nessas variáveis quando submetida a temperatura de $40^{\circ} \mathrm{C}$ (Tabela $3)$.

Carvalho, J. N. da S.; Silva, J. A. B. de; Reis, D. S.; Guimarães, C. C.; Santos, I. E. dos A. 
A variedade BRS011 exibiu melhor desempenho para Massa Fresca do Caule na temperatura de $30^{\circ} \mathrm{C}$, seguida da temperatura de $20^{\circ} \mathrm{C}$ e o desempenho mais baixo na temperatura de $40^{\circ} \mathrm{C}$. Para as variáveis, Massa fresca da folha e da raiz não houve diferenças entre as temperaturas de $20^{\circ}$ e $30^{\circ} \mathrm{C}$ e apenas diferindo da temperatura de $40^{\circ} \mathrm{C}$, na qual houve decréscimo na produção de massa fresca e de massa seca da raiz em todas as variedades.
Não houve interação entre Variedade e Temperatura para as variáveis Altura das plantas, Diâmetro do caule e Número de folhas. No entanto, analisando apenas a interferência da Temperatura, o diâmetro do caule não mostrou alterações na espessura com a variação da mesma.

A Tabela 3 mostra que é possível verificar que a maior temperatura é prejudicial à produção de massa seca; enquanto, as temperaturas de 20 e $40^{\circ} \mathrm{C}$ apresentam efeito positivos quanto à variável citada.

Tabela 3. Massa fresca de caule (g), massa fresca da folha (g), massa fresca da raiz (g) e massa seca da Raiz em função das variedades de milho BRS Assum preto, BRS011 e BRS033 e temperaturas de emergência. Petrolina-PE, em 2015.

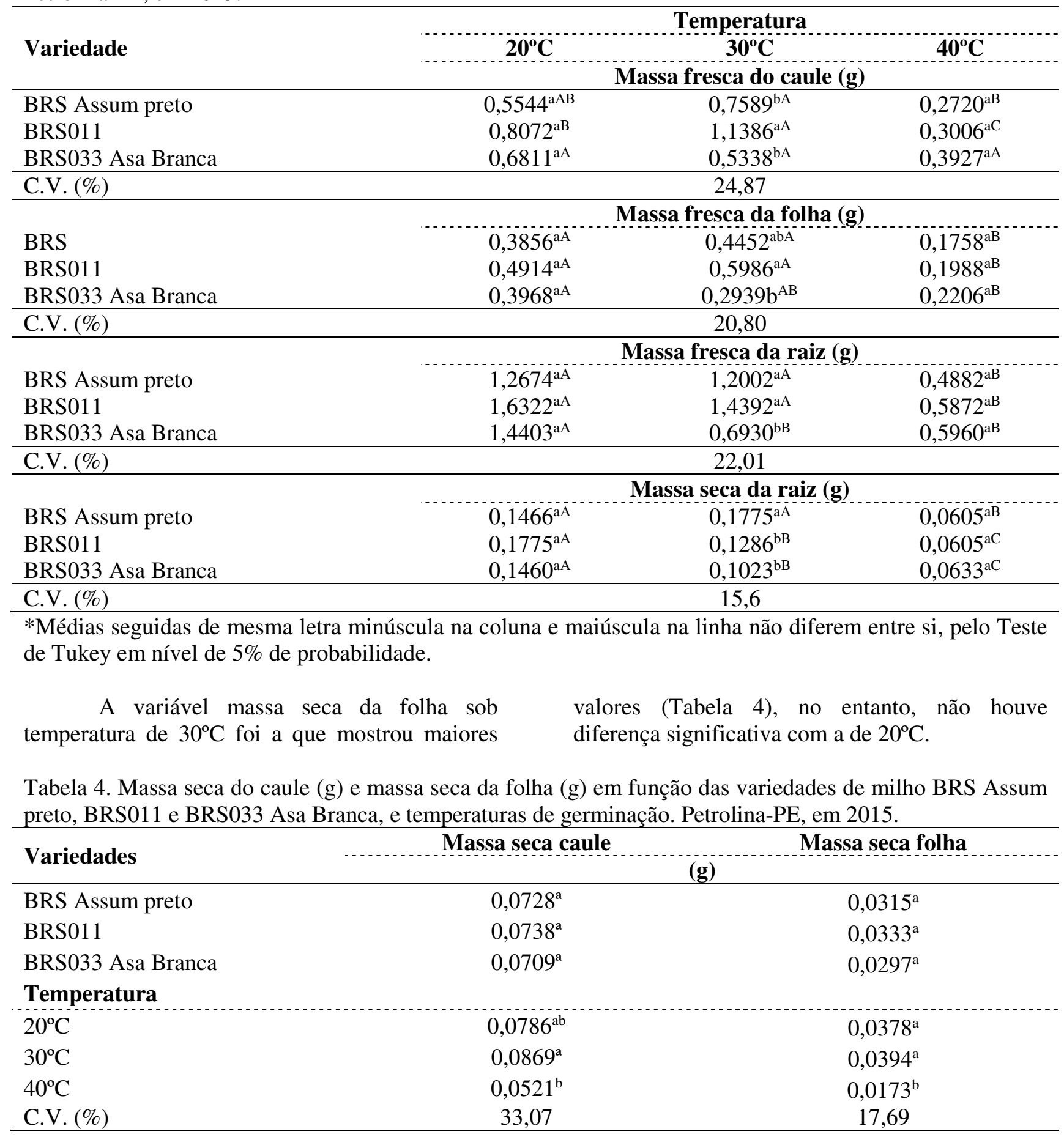

Carvalho, J. N. da S.; Silva, J. A. B. de; Reis, D. S.; Guimarães, C. C.; Santos, I. E. dos A. 
*Médias seguidas de mesma letra não diferem entre si, pelo Teste de Tukey em nível de 5\% de probabilidade.

A Tabela 5 mostra os dados dos aspectos morfológicos das plântulas e verifica-se que as maiores alturas das novas plantas foram obtidas quando seu cultivo foi condicionado à temperatura de $30^{\circ} \mathrm{C}$, seguidas pelas cultivadas em $20^{\circ} \mathrm{C}$ e $40^{\circ} \mathrm{C}$, que não se diferiram entre si.

A maior altura do caule ocorreu também na temperatura de $30^{\circ} \mathrm{C}$ e a menor medida se deu na faixa dos $40^{\circ} \mathrm{C}$. $\mathrm{O}$ Número de folhas não diferiu para as temperaturas mais elevadas e foi superior estatisticamente ao encontrado na temperatura mais baixa.

A temperatura de $30^{\circ} \mathrm{C}$ promoveu um incremento de $50 \%$ na altura das plântulas das variedades em relação as outras temperaturas (Tabela 5). Situação semelhante foi encontrada para a altura do caule que, em média teve um aumento entre 20 a $30 \%$.

Conforme discutido anteriormente, a temperatura de $30^{\circ} \mathrm{C}$ foi a que apresentou os melhores resultados quanto à formação morfológica das plantas.

Tabela 5. Altura das plântulas $(\mathrm{cm})$, comprimento do Caule $(\mathrm{cm})$, Diâmetro $(\mathrm{cm})$ e Número de Folhas em função das variedades de milho BRS Assum preto, BRS011 e BRS033 Asa Branca, e temperaturas de germinação. Petrolina-PE, em 2015.

\begin{tabular}{|c|c|c|c|c|}
\hline Variedades & Altura das plântulas & Altura do caule & Diâmetro & $\begin{array}{l}\text { Número de } \\
\text { folhas }\end{array}$ \\
\hline BRS Assum preto & $20,7711^{a}$ & $5,4611^{\mathrm{a}}$ & $5,4611^{\mathrm{a}}$ & $3,3778^{a}$ \\
\hline BRS011 & $22,3089^{a}$ & $6,5156^{\mathrm{a}}$ & $6,5156^{\mathrm{a}}$ & $3,4889^{\mathrm{a}}$ \\
\hline $\begin{array}{l}\text { BRS033 Asa Branca } \\
\text { Temperatura }\end{array}$ & $23,3222^{\mathrm{a}}$ & $6,1400^{\mathrm{a}}$ & $6,1400^{\mathrm{a}}$ & $3,3111^{\mathrm{a}}$ \\
\hline $20^{\circ} \mathrm{C}$ & $18,7600^{\mathrm{b}}$ & $5,6022^{\mathrm{b}}$ & $2,4413^{\mathrm{a}}$ & $3,0889^{\mathrm{b}}$ \\
\hline $30^{\circ} \mathrm{C}$ & $31,3644^{\mathrm{a}}$ & $8,3789^{\mathrm{a}}$ & $2,7162^{\mathrm{a}}$ & $3,6444^{\mathrm{a}}$ \\
\hline $40^{\circ} \mathrm{C}$ & $16,2778^{b}$ & $4,1355^{\mathrm{c}}$ & $2,4815^{\mathrm{a}}$ & $3,4444^{\mathrm{a}}$ \\
\hline C.V. (\%) & 19,29 & 14,97 & 11,70 & 5,90 \\
\hline
\end{tabular}

*Médias seguidas de mesma letra não diferem entre si, pelo Teste de Tukey em nível de 5\% de probabilidade.

$\mathrm{Na}$ Tabela 6, os resultados relativos à avaliação do parâmetro Clorofila e os valores entre as variedades não foram significativos. Todavia, entre as temperaturas avaliadas, a de $30^{\circ} \mathrm{C}$ se mostrou com maior teor de clorofila $a$ e clorofila total. Em contrapartida, a faixa de $40^{\circ} \mathrm{C}$ produziu as menores quantidades de clorofila.
A temperatura ao interferir na germinação e emergência das plântulas pode influenciar diretamente na síntese de clorofila e assim afetar a atividade fotossintética e consequentemente a produção de açúcar, crescimento e desenvolvimento de plantas.

Tabela 6. Teores de clorofila $a, b$ e total em função das variedades e temperaturas de germinação. PetrolinaPE, em 2015.

\begin{tabular}{lccc}
\hline Variedades & Clorofila a & Clorofila b & Clorofila total \\
\hline BRS Assum preto & $26,7211^{\mathrm{a}}$ & $5,8367^{\mathrm{a}}$ & $32,5578^{\mathrm{a}}$ \\
BRS011 & $28,3567^{\mathrm{a}}$ & $5,8056^{\mathrm{a}}$ & $34,1622^{\mathrm{a}}$ \\
BRS033 Asa Branca & $30,3444^{\mathrm{a}}$ & $6,7300^{\mathrm{a}}$ & $37,0744^{\mathrm{a}}$ \\
Temperatura & & & \\
\hdashline $20^{\circ} \mathrm{C}$ & $28,9433^{\mathrm{ab}}$ & $7,6733^{\mathrm{a}}$ & $36,6166^{\mathrm{a}}$ \\
$30^{\circ} \mathrm{C}$ & $31,4200^{\mathrm{a}}$ & $5,9211^{\mathrm{b}}$ & $37,3411^{\mathrm{a}}$ \\
$40^{\circ} \mathrm{C}$ & $25,0589^{\mathrm{b}}$ & $4,7778^{\mathrm{b}}$ & $29,8367^{\mathrm{b}}$ \\
\hline C.V. $(\%)$ & 13,74 & 18,17 & 13,74 \\
\hline
\end{tabular}

*Médias seguidas de mesma letra minúscula na coluna e maiúscula na linha não diferem entre si, pelo Teste de Tukey em nível de 5\% de probabilidade.

\section{Discussão}

Em virtude de o milho ser uma espécie tropical, a temperatura para emergência das plântulas se enquadra em um intervalo adequado para a germinação das sementes. As variedades estudadas são indicadas para a região semiárida, provavelmente por este motivo não foram verificadas diferenças significativas quanto as

Carvalho, J. N. da S.; Silva, J. A. B. de; Reis, D. S.; Guimarães, C. C.; Santos, I. E. dos A. 
suas velocidades e frequência relativa de geminação.

Esses dados corroboram as pesquisas realizadas por Deng et. al. (2015), que, avaliando o efeito da temperatura no comportamento de germinação de milho branco, amarelo, roxo e vermelho, observaram que a temperatura para o milho apresentar melhor comportamento está na faixa dos $30^{\circ} \mathrm{C}$, demonstrando, assim como no presente estudo, que as temperaturas baixas de $15^{\circ} \mathrm{C}$ e as elevadas de $40^{\circ} \mathrm{C}$, provocam retardo na germinação das sementes, quando comparadas à faixa intermediária.

Sbrussi \& Zucareli (2015), avaliando a qualidade fisiológica de sementes de milho germinadas em altas temperaturas também mostraram decréscimo na germinação de sementes submetidas a temperaturas superiores a $34^{\circ} \mathrm{C}$.

Segundo Brancalion, Novembre \& Rodrigues (2010), trabalhando com espécie de cerrado, região onde $\mathrm{o}$ milho tem muita representatividade em termos de produção, verificaram que o bom desenvolvimento do processo de germinação ocorreu a partir de temperaturas próximas de $30^{\circ} \mathrm{C}$.

Mondo et al. (2010), estudando os efeitos da luz e temperatura na germinação de sementes de quatro espécies de plantas daninhas do gênero Digitaria, observaram que, para todas as espécies avaliadas, sob temperatura constante de $25^{\circ} \mathrm{C}$, a porcentagem e a velocidade de germinação foram inferiores às verificadas sob as temperaturas alternadas de $20-35^{\circ} \mathrm{C}$ e $15-35^{\circ} \mathrm{C}$. Estas, de um modo geral, foram as mais adequadas para a germinação das sementes. Resultado semelhante foi encontrado no presente estudo, em que a menor temperatura inibiu o processo de germinação com consequente redução da frequência relativa e da velocidade de emergência das plântulas.

Geralmente, estudos realizados quanto ao processo de germinação demostram que baixas temperaturas retardam o processo de germinação, assim como a velocidade de formação morfológica das plantas de diversas espécies vegetais.

Sabe-se que a diminuição da temperatura promove uma menor velocidade das atividades bioquímicas e fisiológicas envolvidas no metabolismo das células que atuam na formação das sementes, bem como a capacidade de se multiplicarem e formarem os tecidos; retardando assim o desenvolvimento de órgãos como raiz, folha e caule. Este fato foi comprovado pelo maior período de dias para que as sementes das variedades estudadas germinassem, ou seja, na temperatura de $20^{\circ} \mathrm{C}$ para três variedades houve retardamento do processo de emergências das plântulas.

Para as variedades BRS Assum Preto e BRS011 a temperatura de $40^{\circ} \mathrm{C}$ foi a que promoveu aumento na velocidade de geminação, entretanto, segundo dados que serão mostrados posteriormente, não ocorreu uma correção positiva quanto a formação das novas plântulas, ou seja, a temperatura elevada prejudica a emergência das plântulas e, consequentemente, seu crescimento e desenvolvimento das plantas.

A temperatura de $30^{\circ} \mathrm{C}$ Apresentou TMG intermediário com uniformidade entre as variedades. Segundo Carvalho \& Nakagawa (2000) e Silva, Rodrigues \& Aguiar (2002), a temperatura ótima para germinação total é diferente da ótima para a velocidade de germinação das sementes que apresenta maior. Estes autores ressaltam que em temperaturas mais elevadas a velocidade de absorção de água e das reações químicas é maior, o que justifica as sementes germinarem mais rapidamente quando submetidas a níveis maiores de temperatura.

Segundo Nogueira et al. (2014), em seu estudo sobre o efeito da temperatura e luz na germinação de sementes de Dalbergia cearensis Ducke, verificaram, também, o efeito negativo de baixas e altas na capacidade de emergência e, que a temperatura de $30^{\circ} \mathrm{C}$ e faixas próximas apresentaram os melhores resultados.

O estudo de Pereira \& Bezerra (2013), com Cochlospermum vitifolium (Will.) Sprengel, mostrou que as temperaturas constantes proporcionaram, de forma quantitativa, as maiores médias de germinação, em comparação com a temperatura alternada $\left(20-30^{\circ} \mathrm{C}\right)$. Entretanto, o fato de ocorrer germinação em ambos os regimes e temperatura revela a capacidade da espécie de se adaptar às flutuações térmicas naturais do ambiente. Logo, a semente poder alternar sua eficiência de germinação em reposta a variação de temperatura, entretanto, existem limites quanto a sua capacidade em responder de forma positiva a esta variação.

A variedade BRS033 Asa Branca não mostrou diferenças significativas para a produção de massa fresca do caule com a variação de temperatura. A produção de massa fresca das folhas e da raiz foi maior sob a temperatura mais baixa, bem como para a massa seca da raiz.

Analisando as diferenças entre $o$ comportamento das variedades dentro de cada temperatura, para os $20^{\circ} \mathrm{C}$ as mesmas não apresentaram diferenças significativas para nenhuma das variáveis estudadas na interação Variedade com Temperatura, o mesmo ocorreu 
para os $40^{\circ} \mathrm{C}$. Na faixa dos $30^{\circ} \mathrm{C}$ para a massa fresca do caule e das folhas, a variedade BRS011 foi a que mostrou maior produção, seguida da BRS Assum preto e da BRS033 Asa Branca.

Com relação à massa fresca da raiz, os valores foram decrescentes para as temperaturas, porém não houve significância entre $20^{\circ} \mathrm{C} \mathrm{e} 40^{\circ} \mathrm{C}$, onde a primeira apresentou maior massa para todas as variedades.

Comparando as variedades, BRS Assum preto obteve a maior produção de massa seca de raiz dentro desta faixa de temperatura enquanto que as demais não diferiram estatisticamente. Akinnuoye (2015) encontrou diferenças significativas quando avaliou os diferentes regimes de temperatura, os quais variaram de 20 a $30^{\circ} \mathrm{C}$ constantes e alternando as temperaturas citadas em intervalos frequentes de 12/12 horas.

Observa-se o maior índice de clorofila $b$ nas folhas das variedades de milho, submetidas à temperatura de $20^{\circ} \mathrm{C}$. Silva et al. (2015), em seu estudo com análise de pigmentos fotossintéticos e trocas gasosas em feijão sob condições de variação da temperatura e concentração de $\mathrm{CO}_{2}$, verificaram que a redução de temperatura, ao longo dos cultivos das plantas, promove uma diminuição da síntese e acúmulo de clorofilas $a, b$ e total nas folhas.

Diversas situações de alterações da condição ambiente em que as plantas crescem podem interferir em eventos bioquímicos, fisiológicos entre outros, afetando a absorção de nutrientes, metabolismos de muitos compostos, síntese de estruturas moleculares necessárias as plantas, como por exemplo produção de proteínas, açúcares, síntese das clorofilas $a$ e $b$.

Situações como estresse hídrico podem alterar a capacidade das folhas em produzir e dispor as clorofilas membranas do tilacóides formadoras dos cloroplastos encontrados nas células da folha.

\section{Conclusão}

A temperatura de $30^{\circ} \mathrm{C}$ se mostra como a faixa ideal para a germinação e o desenvolvimento inicial de mudas de milho.

\section{Agradecimentos}

À equipe do Laboratório de Citologia e Fisiologia Vegetal pela colaboração durante a realização do experimento.

\section{Referências}

AKINNUOYE, D. B.; MODI, A. T. 2015. Germination Characteristics of SC701 Maize Hybrid According to Size and Shape at Different
Temperature Regimes. Plant Prod. Sci., n. 18, p. 514-521.

BRANCALION, P. H. S.; NOVEMBRE, A. D. L. C.; RODRIGUES, R. R. 2010. Temperatura ótima de germinação de sementes de espécies arbóreas brasileiras. Revista Brasileira de Sementes, v. 32, n. 4 p. $015-021$.

Brasil. 2009. Ministério da Agricultura, Pecuária e Abastecimento. Regras para análise de sementes. Secretaria de Defesa Agropecuária Brasília: Mapa/ACS. 399p.

BERGAMASCHI, H.; MATZENAUER, R. 2014. O milho e o clima. Porto Alegre: Emater/RSAscar, p.84

CARVALHO, N. M.; NAKAGAWA, J. 2000. Sementes: ciência, tecnologia e produção. Jaboticabal, São Paulo, 2 ed. FUNEPE.

DENG, B.; YANG, K.; ZHANG, Y.; LI, Z. 2015. The effects of temperature on the germination behavior of white, yellow, red and purple maize plant seeds. Acta Physiologiae Plantarum, v. 37, n. 8, p. 1-11.

GUAN, Y.; HU, J.; WANG, X.; SHAO, C. 2009. Seed priming with chitosan improves maize germination and seedling growth in relation to physiological changes under low temperature stress. Seed Science Center, Crosschecked, v. 10, n. 6 , p. 427-433.

MAPA-Ministério da Agricultura e Pecuária. 2015. Milho, 2015. Disponível em: http://www.agricultura.gov.br/vegetal/cultura/mil ho/. Acesso em: 17/08/2015.

MONDO, V. H. V.; CARVALHO, S. J. P.; DIAS, A. C. R.; FILHO, J. M. 2010. Efeitos da luz e temperatura na germinação de sementes de quatro espécies de plantas daninhas do gênero Digitaria. Revista Brasileira de Sementes, v. 32, n. 1, p. 131137.

NOGUEIRA, F. C. B.; GALLÃO, M. I.; Bezerra, A. M. E.; FILHO, S. M. 2014. Efeito da temperatura e luz na germinação de sementes de Dalbergia cearensis Ducke. Ciência Florestal, v. 24, n. 4, p. 997-1007.

PEREIRA, D. S. P.; PEREIRA, M. S.; Bezerra, M. E. 2013. Efeito da luz e da temperatura na germinação de sementes de Cochlospermum vitifolium (Will.) Sprengel. Floresta e Ambiente, v. 20, n. 3, p. 391-397. 
SBRUSSI, C. A. G.; ZUCARELI, C. 2015. Germinação sob altas temperaturas para avaliação do potencial fisiológico de sementes de milho. Ciência Rural, Santa Maria. Ciência Rural, v. 45, n. 10, p. 1736-1741.

SBRUSSI, C. A. G.; ZUCARELLI, C. 2014. Germinação de sementes de milho com diferentes níveis de vigor em resposta à diferentes temperaturas. Revista Ciências Agrárias, v. 35, n. 1, p. 215-226.

SILVA, L. M. M.; RODRIGUES, T. J. D.; AGUIAR, I. B. 2002. Efeito da luz da temperatura na germinação de sementes de aroeira
(Myracrodruon urundeuva Allemão). Revista Árvore, v. 26, n. 6, p. 691-697.

SILVA, F. V. F.; MENDES, B. S.; ROCHA, M. S. R.; NETO, F.B.; BELTR ÃO, N. E. M.; SOFIATTI, V. 2015. Photosynthetic pigments and gas exchange in castor bean under conditions of above the optimal temperature and high $\mathrm{CO}_{2}$. Acta Scientiarum. Agronomy, v. 37, n. 3, p. 331-337.

VAZ-DE-MELO, A; SANTOS, L. D. T.; FINOTO, E. L.; DIAS, D. C. F. S.; ALVARENGA, E. M. 2012. Germinação e vigor de sementes de milho-pipoca submetidas ao estresse térmico e hídrico. Revista Bioscience Journal, v. 28, n. 5, p. 687-695. 